\title{
Experimental study of Steel-Concrete Composite Beams comprised of Fly ash based Geopolymer concrete
}

\author{
Balbir Singh $^{\text {a*}, \text { Ee Loon Tan }}{ }^{a}$, Zhu Pan ${ }^{\text {a }}$, Olivia Mirza ${ }^{\text {a }}$ and Julius Boncato ${ }^{a}$ \\ ${ }^{a}$ Western Syndey University, Australia \\ *corresponding author, balbir.singh@westernsydney.edu.au
}

\begin{abstract}
To combat the present situation of greenhouse gases emission from cement production, a promising solution is to utilise supplementary cementitious by-product materials such as fly ash to produce green concrete known as Geopolymer concrete (GPC). However, despite fly ash based concrete is a promising substitute for ordinary Portland cement (OPC) concrete, it is not yet being utilised to its full potential for structural applications. And so, to utilise green concrete to its full potential, this paper aim is to conduct an experimental study that will integrate fly ash based concrete within steel-concrete composite beams. The research will include casting of composite beams with GPC mix, and an OPC concrete as a reference mix designed according to British Standards. To determine the ultimate moment capacity, a total of Four (4) composite beams comprised of coventional and Bondek steel profile concrete slab are designed and tested according to Australian Standards. From the test results, it was found that composite beam with conventionalconcrete slab outperformed the beams with Bondek profile sheeting. Also, regarding of ultimate bending moment capacity, the composite beam with geopolymer concrete experienced almost identical to OPC composite beam.
\end{abstract}

Keywords: Sustainability; Geopolymer concrete; Fly ash; Steel-concrete composite beam.

\section{Introduction}

The Portland cement is one of the major used building materials and has been incorporated virtually in all the infrastructure development around the world. According to [1], the global production of cement is over four billion tonnes per annum and, China has become the leading cement producer followed by India contributing the total production of cement globally up to $57.3 \%$ and $6.6 \%$, respectively. However, due to excessive production, the cement industry contributes up to $5-7 \%$ of greenhouse gas $\mathrm{CO}_{2}$ emission [2]. Consequently, to mitigate the presented situation great efforts are made to study the benefits of incorporating by-products or waste materials as a binder to produce the concrete.

One major advantage of using Fly ash as a primary concrete binder is that it's abundantly available and due to lack of utilization, it is considered as waste and dumped into the landfill. Only $26 \%$ of total fly ash produced annually in the United States has been used for construction practices and, rest of it is being disposed of as a waste material [3], causing further environmental damages.

Introduced in 1970's by Joseph Davidovits, Geo-polymer concrete encompass the reaction of aluminosilicate binders that are rich in silica $\left(\mathrm{Si}^{4+}\right)$ and alumina $\left(\mathrm{Al}^{3+}\right)$ such as fly ash combined with highly concentrated alkaline solution (typically $\mathrm{Na}$ or K-based solutions). The reaction of these elements results in polymeric chains with a three dimensional amorphous to semi-crystalline microstructure [4]. Despite proven to exhibit excellent compressive strength, low drying shrinkage, resistance to sulphate attack and good acid resistance [5], fly ash based geopolymer concrete has not been used to its full potential. Because the relatively high temperatures are 
beneficial for overcoming the activation barrier of fly ash [6], which has become a major obstacle for it to be widely accepted for larger structural applications. And, for cast-in-place applications, geopolymer concrete requires to be cured at ambient temperatures. Thus, for the purpose of this study fly ash based geopolymer concrete mix is designed particularly to be cured and cast in ambient temperature and incorporated into steel-concrete composite structure to experimentally determine the ultimate flexural behaviour of the beams.

\section{Experimental Program}

\subsection{Materials}

The primary binder used for geopolymer concrete is a low calcium Class-F fly ash obtained from coal power plant in Queensland, Australia. Grounded Blasted Furnace Slag (GBFS) was utilised as an additive that is known to cure geopolymer concrete at ambient temperatures. The binder ratio of 90:10 was applied, that is $90 \%$ fly ash and $10 \%$ slag content. For conventional concrete, locally available all general purpose cement was used. The chemical composition of fly ash, slag and cement is presented in Table 1.
The aggregates used within the concrete mix designs consisted of both Fine aggregate (Nepean river sand) and Coarse aggregate (20 mm Basalt rock also know as Blue Metal). To improve the flowability of Geopolymer concrete, superplasticiser (SP) known as SIKA Visco Crete PC-HRF-2 was utilised.

\subsection{Experimental Test}

\subsubsection{Concrete Mixing}

The geopolymer concrete was mixed and poured on site and cured at ambient temperatures. To begin concrete mixing, all the dry component (Fly Ash, GBFS, Fine and Coarse aggregate) was mixed completely before adding any liquid component. Once the dry material was thoroughly mixed, then the liquid components were added to the concrete mix using 50:50 method. That is, $50 \%$ of AS was added in the concrete mixer followed by $50 \%$ of $\mathrm{SP}$ was added and mixed. Then the remaining $50 \% \mathrm{AS}$ and $50 \% \mathrm{SP}$ was poured into the mixer and mixed and finally extra water was added to the concrete mix until the good consistency was achieved.

The OPC concrete was designed and mixed according to British Standards. Table 2, provides concrete mix design.

Table 1. Chemical composition of binders

\begin{tabular}{c|c|c|c|c|c|c|c|c}
\hline Binder & $\mathrm{SiO}_{2}$ & $\mathrm{Al}_{2} \mathrm{O}_{3}$ & $\mathrm{Fe}_{2} \mathrm{O}_{3}$ & $\mathbf{C a O}$ & $\mathrm{Na}_{2} \mathrm{O}$ & $\mathbf{M g O}$ & $\mathbf{S O}_{3}$ & $\mathbf{L O I}$ \\
\hline $\begin{array}{c}\text { Fly } \\
\text { Ash }\end{array}$ & 52.2 & 24.0 & 13.7 & 3.18 & 0.65 & 1.32 & 0.2 & 1.1 \\
\hline Slag & 32.6 & 13.4 & 0.35 & 43.0 & 0.20 & 5.5 & 3.4 & 0.1 \\
\hline Cement & 18.2 & 4.9 & 2.6 & 60.7 & 0.2 & 1.0 & 2.2 & 3.0 \\
\hline
\end{tabular}

Table 2. Concrete Mix design

\begin{tabular}{c|c|c|c|c|c|c|c|c}
\hline \multirow{2}{*}{$\begin{array}{c}\text { Mix } \\
\text { ID }\end{array}$} & \multicolumn{8}{|c}{ Mix Proportion (kg) } \\
\cline { 2 - 9 } & C $^{*}$ & FA & Slag & CA & SD & AS & W & SP \\
\hline GPC & - & 292 & 35.52 & 995 & 584 & 146.33 & 9.79 & 6.50 \\
\hline OPC & 308 & - & - & 248 & 678 & - & 170 & - \\
\hline
\end{tabular}

$\mathrm{C}^{*}=$ Cement, $\mathrm{FA}=$ Fly Ash, $\mathrm{CA}=$ Coarse Aggregate, $\mathrm{SD}=$ Sand,

$\mathrm{AS}=$ Alkaline Solution, $\mathrm{W}=$ water and $\mathrm{SP}=$ Superplasticiser 


\subsubsection{Test Specimens design specifications}

A total of four (4) steel-concrete composite beam specimens were fabricated and tested according to Australian Standard AS 2327.1:2003. The geometry of all the specimen are identical in such that concrete slab was comprised of $4600 \times 600 \times 130 \mathrm{~mm}$ and 200UB29.8 steal beam $4600 \mathrm{~mm}$ in length was conjoined to the concrete slab by the mean of $19 \mathrm{~mm}$ diameter headed shear stud. To achieve full shear connection, a total of 30 shear studs were welded onto steel beam with the spacing of $200 \mathrm{~mm}$ centre to centre. Also, N12 steel reo bars were used to form steel mesh to provide flexural reinforcement in the concrete slab. Also, for each concrete mix one conventional and one composite concrete slab was designed. For the composite concrete slab, $1 \mathrm{~mm}$ thick galvanised Bondek steel profile sheet were laid perpendicular to the beam. Fig. 1. illustrates the design specification both conventional concrete slab and Bondek slab composite beam specimens.

To study the mechanical properties such as Compressive Strength and Modulus of Elasticity of concrete, 200×100 mm cylinder specimens were poured and cured wrapped in plastic film.

\subsubsection{Testing Procedures}

The test rig was comprised of Hydraulic Oscillator with load capacity of $1000 \mathrm{kN}$. The beam was simply supported at $4000 \mathrm{~mm}$, and both ends of the specimens was roller support as seen Fig.2. A loading plate with a mass of 38 $\mathrm{kg}$ was placed in the middle of the beam and downward axial loading was applied at the constant rate of $0.027 \mathrm{~mm} / \mathrm{sec}$. At the beginning of the test initial loading of $30 \mathrm{kN}$ and $20 \mathrm{kN}$ was applied to conventional and bondek specimen, respectively, to check all the instruments attached are functioning correctly.
The testing machine for cylinder testing involved Intron Universal Testing machine with a $1000 \mathrm{kN}$ capacity and loading rate of 20 $\mathrm{MPa} /$ min was adopted.

\section{Results and Discussions}

\subsection{The Mechanical properties of Concrete}

The cylinder tests for compressive strength and Modulus of Elasticity was performed in accordance with Australian Standard (A.S) 1012.8.1:2014. Modulus of Rupture (MOR) beam test was carried out in accordance with A.S 1012.11:2002. The compressive test was carried out for curing cycle 28 days and on the day of beam test whereas Modulus of Elasticity was carried out on 28 day curing cycle.

The test results for conventional concrete and Geopolymer concrete is summarised in Table 3. From the test results, it can be seen that geopolymer concrete achieved compressive strength of $32 \mathrm{MPa}$ for 28 days according to its design strength. Whereas, OPC achieved slight higher compressive strength of $43 \mathrm{MPa}$. Furthermore, compressive strength on the beam test day for both OPC and GPC had very similar strength of $43 \mathrm{MPa}$ and $41 \mathrm{MPa}$, respectively.

Regarding Modulus of Elasticity, since its directly related to compressive strength behaviour of the concrete thus similar pattern was observed where the result obtained by OPC was higher in comparison to geopolymer concrete. The result obtained by OPC and GPC is $36776 \mathrm{MPa}$ and $22941 \mathrm{MPa}$, respectively.

Table 3. Mechanical properties of concrete

\begin{tabular}{c|c|c|c}
\hline \multirow{2}{*}{$\begin{array}{c}\text { Concrete } \\
\text { type }\end{array}$} & \multicolumn{2}{|c|}{$\begin{array}{c}\text { Compressive } \\
\text { Strength (MPa) }\end{array}$} & $\begin{array}{c}\text { Modulus of } \\
\text { Elasticity (MPa) }\end{array}$ \\
\cline { 2 - 4 } & 28 Days & Test Day & 28 days \\
\hline OPC & 42.9 & 43 & 36776 \\
\hline GPC & 32.34 & 41.50 & 22941 \\
\hline
\end{tabular}



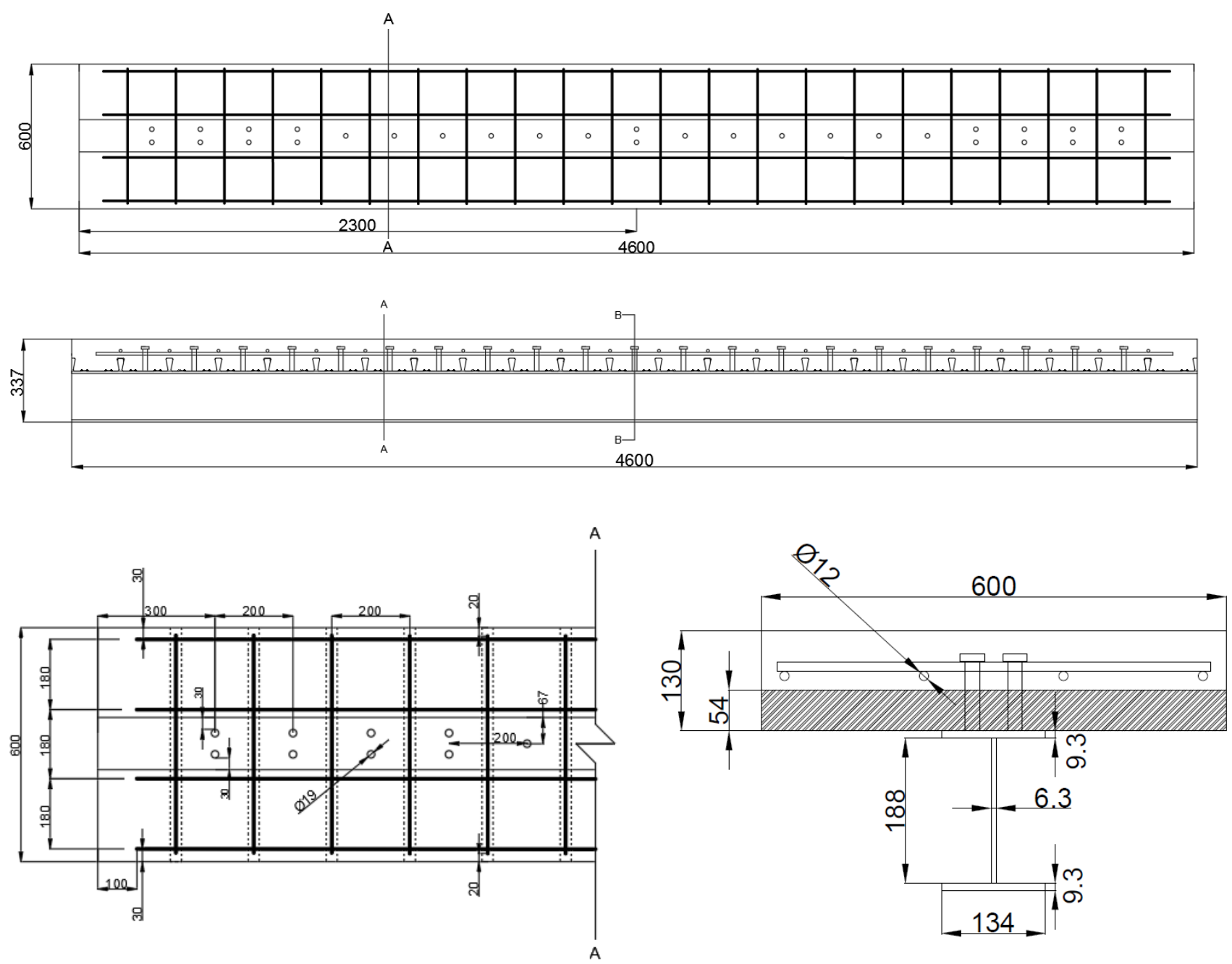

Fig. 1. Composite beam specifications

\subsection{Composite Beams}

The result obtained from beam testing is summarised in Table 4. Overall, it can be seen that the beams with conventional concrete slab outperformed the beam with composite concrete Bondek slab for both OPC and GPC. That is, specimen OPC-C experienced load capacity of $270 \mathrm{kN}$ with deflection of $164 \mathrm{~mm}$ in comparison to OPC-B which achieved load capacity of $229 \mathrm{kN}$ with deflection of $123 \mathrm{~mm}$. Similarly, specimen GPC-C experienced higher load capacity as compare to specimen GPC-B. This is due to the presence of embossments which reduced the amount of concrete within the concrete slab, therefore, reduced the overall beam's capacity.

Also, comparing only conventional concrete beams for both concrete types then it can be seen that both experienced almost the same load capacity whereas OPC achieved only $1.85 \%$ higher than GPC-C. However, on the contrary GPC beam with Bondek experienced higher load capacity than specimen OPC-B. But due to sudden failure of specimen GPC-B achieved the least amount of mid-span deflection as seen in Fig. 3.

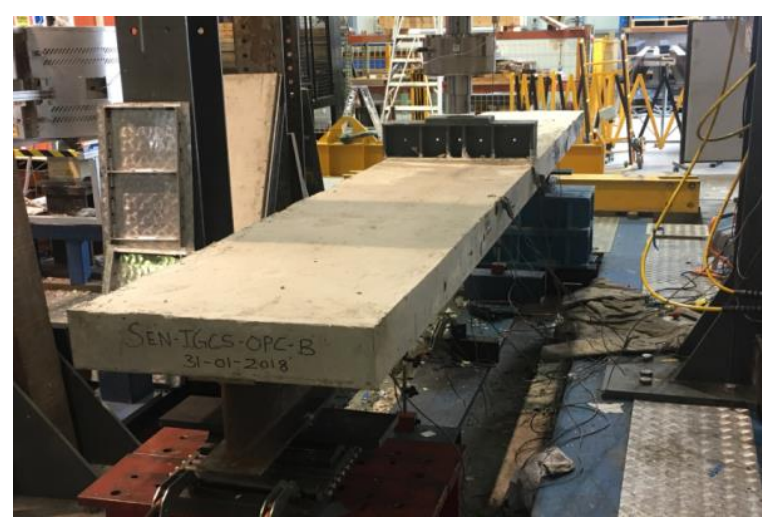

Fig. 2. Composite beam test set-up 
Table 4. Beam test result summary

\begin{tabular}{c|c|c|c|c}
\hline $\begin{array}{c}\text { Specim } \\
\text { en ID }\end{array}$ & $\begin{array}{c}\text { Max } \\
\text { Load } \\
\text { Capaci } \\
\text { ty (kN) }\end{array}$ & $\begin{array}{c}\text { Mid } \\
\text { Span } \\
\text { Deflecti } \\
\text { on } \\
(\mathbf{m m})\end{array}$ & $\begin{array}{c}\text { Ultima } \\
\text { te } \\
\text { Mome } \\
\mathbf{n t} \\
(\mathbf{k N . m )}\end{array}$ & $\begin{array}{c}\text { Maximu } \\
\mathbf{m} \\
\text { Curvatu } \\
\mathbf{r e}\left(\mathbf{x} \mathbf{~ 1 0}^{-}\right. \\
\mathbf{6}_{\mathbf{m}}^{-1} \mathbf{)}\end{array}$ \\
\hline OPC-C & 270 & 164 & 270 & 198 \\
\hline OPC-B & 229 & 123 & 229 & 204 \\
\hline GPC-C & 265 & 157 & 265 & 257 \\
\hline GPC-B & 250 & 75 & 250 & 253 \\
\hline
\end{tabular}

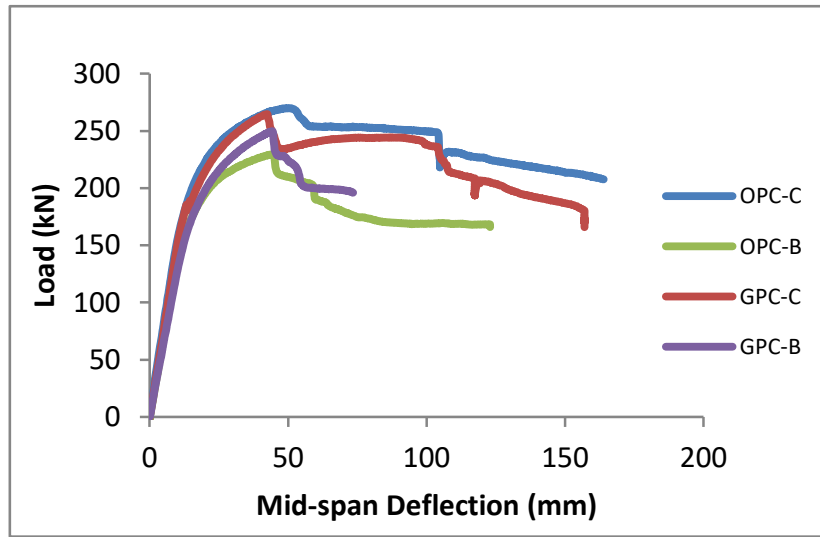

Fig. 3. Load vs Mid-span deflection

Furthermore, the moment vs curvature of all beams specimens is shown in Fig. 4. It can be seen that initial stiffness for all the beams are very similar and until the moment of $200 \mathrm{kN} . \mathrm{m}$ all the beams are within the elastic region, and from there onwards the beams are behaving differently to one another. regarding ductility specimen with geopolymer concrete were more ductile as compare to the specimen with normal concrete. Overall, comparing conventional concrete slab specimens, GPC-C achieved $23 \%$ higher flexural capacity then OPC-C. A Similar result is seen when comparing specimens with the Bondek profile concrete slab. That is GPC-B achieved 19\% higher flexural capacity in comparison to OPCB. Another important observation is that all the beams except OPC-C experienced sudden drop after achieved its ultimate moment capacity due to flexural concrete cracking.

\section{Conclusion}

In conclusion, the experimental study was conducted to determine the ultimate flexural capacity of the steel-concrete composite beams incorporating enviromental friendly geopolymer concrete. Overall, it was observed that the beam specimens with conventional slab outperformed specimens incorporating Bondek concrete slab for both concrete types that is due to the presence of profile sheet flanges that reduces the amount of concrete within the concrete slab hence reducing its ultimate capacity. Also, it was observed that geopolymer concrete achieved the higher flexural capacity for both conventional and composite concrete slab. At last, it can be concluded that environmental friendly geopolymer concrete has great potential and can be a great substitute for larger structural application as compared to normal cement concrete that contributes a significant amount of greenhouse emission globally.

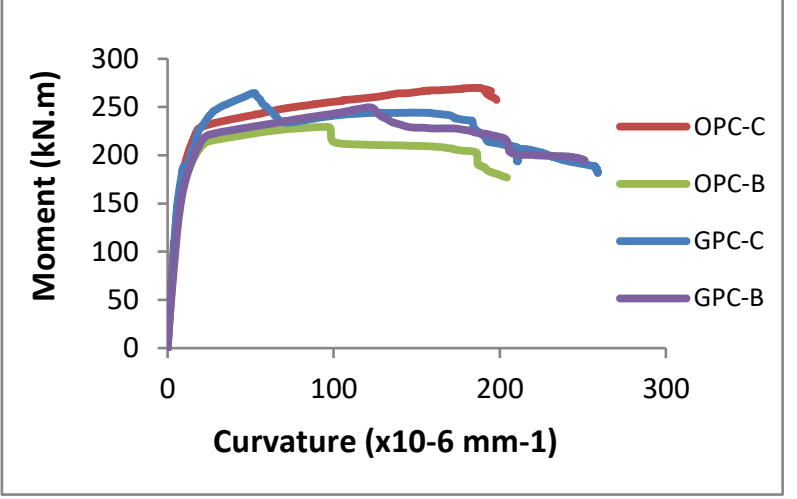

Fig. 4. Moment vs Curvature

\section{References}

[1] Bourtsalas AC, Zhang J, Castaldi M, Themelis NJ. Use of non-recylced plastic and paper as alternative fuel. Journal of Cleaner Production, 2018;181:8-16.

[2] Turner L, Collins F. Carbon dioxide equivalent (CO2-e) emissions: A comparison between geopolymer and OPC cement concrete. Construction and Building Materials, 2013;43:125-130.

[3] Dermats D, Meng X. Ultilisation of fly ash for stabilization/solidification of heavy metal contaminated soils. Engineering Geology, 2003;70:377.394.

[4] Davidovits J, Cordi S. Synthesis of new high temperature geo-polymer for reinforced 
plastsic/composites, SPE PACTEC, 1979:79:151-154.

[5] Albitar M, Visintin P. Assessing behaviour of fresh and hardened geopolymer concrete mixed with class-F fly ash. Journal of Civil engineering, 2015;19:1445-1455.

[6] Rickard DA, Williams R, Temuujin J, Riessen van A. Assessing the suitability of three Australian fly ashes as an aluminosilicate source of geopolymers in high temperature applications, Material Science and Engineering, 2011;528:3390-3397. 